\title{
Promovendo a Educação Financeira para Estudantes Surdos: Utilizando a Perspectiva Etnomatemática em um Produto
}

\section{Educacional}

\author{
Promoting Financial Education to Deaf Students: Using an Ethnomathematical \\ Perspective in an Educational Product
}

\begin{abstract}
Rodrigo Carlos Pinheiro ${ }^{1}$
Milton Rosa ${ }^{2}$

\section{Resumo}

Inspirados por uma pesquisa de mestrado profissional em Educação Matemática relacionada com as contribuições do Programa Etnomatemática para o desenvolvimento da educação financeira de alunos Surdos que se comunicam em Libras, elaboramos um produto educacional direcionado para professores que lecionam ou pretendem lecionar para esse público especifico de estudantes. Dessa maneira, apresentamos, nesse artigo, as características desse produto educacional, o seu objetivo e como foi elaborado. Além disso, abordamos os conceitos e teorias essenciais em relação aos Surdos, à Cultura Surda, ao Programa Etnomatemática e às suas contribuições para desenvolver a Educação Financeira dessa população escolar. Por fim, mostramos a relevância e o potencial desse produto educacional, bem como as suas contribuições pedagógicas para que os professores possam proporcionar uma formação inclusiva e de qualidade para os seus alunos Surdos.
\end{abstract}

Palavras-chave: Alunos Surdos. Educação Financeira. Libras. Produto Educacional. Programa Etnomatemática.

\begin{abstract}
Inspired by master's degree research in Mathematics Education related to contributions by the Ethnomathematics Program for the development of the financial education of Deaf students who communicate in Libras (Brazilian Sign Language) we developed an educational product useful for teachers who teach or intend to teach for this specific student population. In this article, we discuss the characteristics of this educational product, its purpose and how it was elaborated. In addition, we approach the essential concepts and theories regarding the Deaf Culture, the Ethnomathematics Program and their contributions to developing the Financial Education of this school population. Finally, we show the relevance and potential of this educational product as well as its pedagogical contributions so that teachers can provide an inclusive and quality education for their Deaf students.
\end{abstract}

Keywords: Deaf Students. Financial Education. Brazilian Sign Language (Libras). Educational Product. Ethnomathematics Program.

\footnotetext{
${ }^{1}$ Mestre em Educação Matemática, Professor de Matemática, Secretaria Estadual de Educação de Minas Gerais, rodrigopinheiro506@gmail.com.

${ }^{2}$ Doutor em Educação e Liderança Educacional, Professor Adjunto IV, Departamento de Educação Matemática (DEEMA), Universidade Federal de Ouro Preto (UFOP), milton@ cead.ufop.br.
} 


\section{Introdução}

As práticas educacionais e as concepções de educação que as fundamentam são diversas. Portanto, a educação pode ser entendida como uma estratégia de estímulo ao desenvolvimento individual e coletivo, cujas práticas são geradas pelos membros de grupos culturais distintos com o objetivo de se firmarem e avançarem pessoal e profissionalmente para que possam satisfazer as suas necessidades de sobrevivência e transcendência (D'AMBROSIO, 1996).

Nesse sentido, é importante que a concepção de educação considere os aspectos histórico e cultural de uma determinada organização social para a proposição de objetivos educacionais. Nessa abordagem, a educação pode ser conceituada como uma "estratégia da sociedade para facilitar que cada indivíduo atinja o seu potencial e para estimular cada indivíduo a colaborar com outros em ações comuns na busca do bem comum" (D’AMBROSIO, 1996, p. 68).

Por meio dessa perspectiva de educação, entendemos que é importante que os professores (re)conheçam os seus alunos de maneira ampla, ou seja, existe a necessidade de que esses profissionais conheçam a língua de seus educandos, as suas potencialidades e limitações e, também, as suas histórias, experiências e vivências.

Desse modo, elaboramos um produto educacional, que se originou de uma pesquisa de Mestrado Profissional em Educação Matemática, conduzida pelo primeiro autor sob a orientação do segundo. Assim, esse estudo foi realizado com 20 alunos Surdos matriculados na Educação de Jovens e Adultos (EJA), do Ensino Fundamental II, de uma escola pública, especializada em alunos Surdos, localizada na região metropolitana de Belo Horizonte, Minas Gerais.

O produto educacional descrito nesse artigo é um recorte dessa dissertação de mestrado, que investigou as contribuições do Programa Etnomatemática para o desenvolvimento da Educação Financeira de alunos 
Surdos que se comunicam em Libras ${ }^{3}$. Portanto, relatamos brevemente, nesse artigo, alguns conceitos indispensáveis para que os professores possam promover o desenvolvimento da Educação Financeira de seus alunos Surdos, de acordo com a perspectiva do Programa Etnomatemática.

Dessa maneira, esse produto possui o formato de um caderno de sugestões para professores, que se inicia com a apresentação de informações essenciais sobre os alunos Surdos. Em seguida, descreve as semelhanças e as diferenças entre os Surdos e os deficientes auditivos, apresentando, também, um breve relato histórico sobre a educação de Surdos no Brasil, bem como uma conceituação da Libras e da Cultura Surda. Na sequência, são apresentadas informações referentes ao Programa Etnomatemática e à Educação Financeira para alunos Surdos.

Esse caderno de sugestões foi finalizado com a apresentação de diversas atividades matemáticas relacionadas com a História da Moeda, o Sistema Monetário Brasileiro, a Porcentagem, o Lucro e o Desconto. O objetivo dessas atividades foi auxiliar os estudantes Surdos a alcançarem o sucesso acadêmico no aprendizado da Matemática para que pudessem desenvolver a sua educação financeira.

Além dos textos, a estrutura desse produto também contém caixas de diálogo denominadas de Dicas, Lembretes e Sugestões, que possuem informações úteis e importantes para que os professores e/ou demais usuários possam se orientar com a relação à elaboração das atividades a serem propostas em sala de aula.

Após essa breve descrição da estrutura organizacional desse produto, apresentamos alguns conceitos essenciais sobre os alunos Surdos, o significado da Libras e da Cultura Surda. Posteriormente, destacamos como o Programa

\footnotetext{
${ }^{3}$ A Língua Brasileira de Sinais (LIBRAS) é "reconhecida como [uma] língua, como todas as outras línguas orais, com estruturas gramaticais próprias, [então] perde o status de mímica e gesto, passando a não ser considerada como [uma] linguagem" (ALMEIDA, 2013, p. 23).
} 
Etnomatemática ${ }^{4}$ pode ser utilizado como uma ponte para desenvolver a educação financeira dos estudantes Surdos por meio de sua ação pedagógica. Finalizando, mostramos a relevância e potencial desse produto educacional, bem como as suas contribuições pedagógicas para que os professores possam proporcionar uma formação inclusiva e de qualidade para os alunos Surdos.

\section{Conhecendo melhor os alunos Surdos}

Por meio do relato histórico da Educação para Surdos, verifica-se a longa trajetória desse povo para alcançar os seus direitos e a sua cidadania. A história também mostra que foi somente no século XV que houve iniciativas direcionadas para a educação dos Surdos, na maioria das vezes, por objetivos e razões que nem sempre eram educacionais.

Por outro lado, a primeira escola para Surdos no Brasil foi o Imperial Instituto Nacional para Surdos-Mudos, atualmente conhecido como Instituto Nacional de Educação de Surdos (INES). Esse instituto foi inaugurado com uma filosofia de ensino baseada na metodologia francesa trazida por Ernest Huet, um professor Surdo de origem francesa. Por conseguinte, esse professor trouxe para o Brasil o alfabeto manual e alguns sinais franceses para que a educação dos Surdos fosse realizada com a utilização da língua de sinais.

Contudo, após o Congresso de Milão, em 1880, esse instituto brasileiro aderiu à filosofia oralista (STROBEL, 2009). Nesse contexto, é importante ressaltar que o oralismo defende a predominância da voz, pois se baseia na crença de que a língua oral é a única possibilidade de comunicação e desenvolvimento cognitivo para os indivíduos Surdos. Então, na oralidade, a Língua de Sinais deve ser evitada, pois dificulta o desenvolvimento da oralização dos Surdos (PERLIN, 2002). Em consequência, a:

\footnotetext{
${ }^{4}$ Etnomatemática pode ser definida como um “(...) programa de pesquisa em história e filosofia da Matemática, com implicações pedagógicas, que se situa num quadro muito amplo. Seu objetivo maior é dar sentido a modos de saber e de fazer das várias culturas e reconhecer como e por que grupos de indivíduos, organizados como famílias, comunidades, profissões, tribos, nações e povos, executam suas práticas de natureza Matemática, tais como contar, medir, comparar, classificar" (D'AMBROSIO, 2008, p. 7).
} 
(...) educação do surdo reduziu-se ao ensino da oralização, os professores surdos foram expulsos, a língua de sinais foi banida e a comunidade surda foi excluída da política das instituições de ensino, por ser considerada um perigo para o desenvolvimento da linguagem oral (SACHKS, 1998). Em resultado da concentração exclusiva da educação na oralização, o nível educacional do surdo caiu muito abaixo dos ouvintes (CAPOVILLA, 2000, p. 101).

Consequentemente, no início da década de 1970, pesquisas e investigações foram realizadas na área da Linguística, que buscavam o desenvolvimento de instrumentos pedagógicos para suprir as lacunas deixadas pelo Oralismo. Nesse período, surgiu a filosofia educacional denominada Comunicação Total (BORDINHON, 2010), que possibilitou o "uso de todos os meios [instrumentos] que possam facilitar a comunicação, da fala sinalizada, a uma série de sistemas artificiais até os sinais" (CAPOVILLA, 2000, p. 104).

No entanto, após a condução de vários estudos, os pesquisadores e educadores constataram a inviabilidade da prática denominada bimodalismo, que consiste na utilização simultânea de duas línguas (CAPOVILLA, 2000), uma oral e a outra sinalizada, como, por exemplo, o Português e a Libras, pois alegavam que a preservação da estrutura dessas duas línguas era impraticável (FERREIRA BRITO, 1993).

Esse contexto possibilitou que, desde a década de 1980, uma nova filosofia educacional fosse disseminada no mundo: o Bilinguismo. Essa proposta educacional recomenda que os Surdos sejam instruídos em duas línguas, pois visa possibilitar o seu acesso aos contextos social e escolar. Nesse sentido, essa proposta considera a Língua de Sinais como a primeira língua, sendo a língua materna, o português, como o segundo idioma.

O pressuposto principal dessa proposta é que os Surdos sejam bilíngues, pois é importante que essas pessoas adquiram a língua de sinais como o idioma materno e a língua oficial de seu país como o segundo idioma (PERLIN; STROBEL, 2009). Ressaltamos que, no bilinguismo, a língua de sinais é importante para o desenvolvimento dos Surdos, pois essa língua desempenha uma função comunicacional que estimula do desenvolvimento cognitivo e social em todos os campos do conhecimento (BRITO, 1993). 
Além dessa questão histórica, é importante entender os conceitos e as nomenclaturas que são adequadas e inadequadas ao nos referirmos às pessoas Surdas. Por exemplo, o termo deficiência auditiva é utilizado para indicar a perda de audição ou a diminuição na capacidade de escutar os sons. Essa deficiência está relacionada com os problemas que ocorrem no ouvido e que podem prejudicar a audição em maior ou menor grau (REDONDO; CARVALHO, 2000). Assim, a perda da audição pode ser considerada como uma deficiência sensorial que ocorre, em um ou em ambos os ouvidos, em grau leve, moderado, severo ou profundo (BISOL; VALENTINI, 2011a).

Dessa maneira, no âmbito da medicina, o termo surdo é utilizado para caracterizar a surdez profunda enquanto o termo deficiente auditivo é utilizado para caracterizar uma deficiência auditiva leve ou moderada. Do ponto de vista clínico e cultural, alguns termos utilizados cotidianamente são considerados inadequados, como, por exemplo, surdos-mudos, mudos ou mudinhos. Alertamos que o termo surdo-mudo não deve ser utilizado, pois a surdez não acarreta perdas no aparelho fonador dos indivíduos.

Nesse sentido, os Surdos não desenvolveram a capacidade de falar pelo fato de não ouvirem e não porque as suas cordas vocais foram comprometidas por causa da surdez (HONORA; FRIZANCO, 2009). Por outro lado, os mudos são os indivíduos privados da utilização das palavras por um defeito orgânico ou por uma causa psíquica, que os impossibilitam de se expressarem por meio da fala (FERREIRA, 2000).

Após a condução de muitos estudos, a sociedade começou a se conscientizar de que essas nomenclaturas eram inapropriadas, pois o aparelho fonador dos Surdos era preservado. Então, na atual conjuntura, os Surdos são considerados diferentes (MOURA, 2000), pois possuem uma maneira diferenciada daquela utilizada pelos ouvintes para se comunicarem, apreenderem, entenderem e compreenderem o mundo.

Nesse sentido, a surdez pode ser considerada como uma diferença cultural, pois os membros da Cultura Surda possuem a sua própria língua gestual 
e visual (KYLE, 1999). Por conseguinte, esses membros defendem a utilização do termo Surdo, que caracteriza os indivíduos participantes de uma cultura que possui uma língua própria e que desenvolveram características socioculturais específicas que os identificam.

\section{Língua Brasileira de Sinais - Libras}

Historicamente, Moura (2000) afirma que foi a partir da miscigenação da antiga Língua de Sinais Brasileira com a Língua de Sinais Francesa que se originou a Língua Brasileira de Sinais, denominada de Libras. No início da década de 2000, a Comunidade Surda do Brasil, as Associações de Surdos e a Federação Nacional de Educação e Integração dos Surdos (FENEIS) se consagraram vitoriosos em sua luta pela valorização da língua de sinais e pela sua importância na área educacional (DINIZ, 2010). Então, em 2002, a Libras foi reconhecida como um meio legal de comunicação e expressão utilizada pelas Comunidades Surdas no Brasil.

Consequentemente, em 24 de abril de 2002, a Lei ํo 10.436 foi promulgada e estabeleceu, em seu parágrafo único, que a Língua Brasileira de Sinais é uma forma de comunicação e expressão, bem como um sistema linguístico de natureza visual-motora que possui uma estrutura gramatical própria. Desse modo, a Libras é constituída por um sistema linguístico de transmissão de ideias e fatos que são oriundos das comunidades brasileiras de pessoas Surdas (BRASIL, 2002).

Em 2005, com o Decreto no 5.626, a Língua Brasileira de Sinais se tornou uma disciplina obrigatória nos cursos de licenciatura e fonoaudiologia (BRASIL, 2005). Consequentemente, a Libras assumiu um papel linguístico de destaque na educação brasileira, gerando oportunidades de socialização, interação e participação dos Surdos em qualquer espaço sociocultural (ALMEIDA, 2013).

Contudo, é importante enfatizar que a Libras não pode ser considerada como o alfabeto manual ou a datilologia, que é um sistema simbólico e icônico que representa as letras do alfabeto das línguas orais, em sua forma escrita, por 
meio das mãos. Então, esse alfabeto é utilizado em virtude da inexistência ou do desconhecimento de um sinal equivalente à palavra ou conceito na língua de sinais, como, por exemplo, para os nomes próprios, para os títulos de trabalhos ou para a explicação do significado de um sinal para um ouvinte que conhece o alfabeto manual (BISOL; VALENTINI, 2011b).

Sob outra perspectiva, o alfabeto manual de Libras consiste na soletração de letras e numerais com as mãos. Assim, como no alfabeto, os números também são representados manualmente na Libras. Na Libras, os sinais são formados por meio das articulações com as mãos e com o corpo, que dependem da combinação de três aspectos: a) formatos específicos realizados com as mãos, b) determinados lugares do corpo ou em frente ao corpo em que o sinal é executado e c) movimentos das mãos.

Dessa maneira, é necessário destacar que a principal característica da Língua Brasileira de Sinais é a sua modalidade gestual-visual-espacial. No entanto, ainda persiste a percepção equivocada de que os sinais realizados para comunicação são somente desenhos realizados no ar ou por meio de mímicas (QUADROS; KARNOPP, 2004).

A Libras, como qualquer outra língua, também apresenta variações e dialetos regionais. Por exemplo, as variações na representação dos sinais nas regiões de um mesmo país são denominadas de Variações Regionais. As variações que existem na configuração das mãos e/ou nos movimentos sem que haja modificações no sentido do sinal são denominadas de Variações Sociais. De um modo semelhante, com o passar do tempo, um sinal pode sofrer alterações, denominadas de Mudanças Históricas, que são provenientes dos costumes e dos hábitos das gerações que os utilizam (STROBEL; FERNANDES, 1998).

Destacamos que, as pessoas ouvintes que não se comunicam em Libras também podem conversar com os Surdos por meio do Intérprete de Língua de Sinais. Então, quando essa comunicação acontece, a Libras pode ressignificar as relações sociais entre os Surdos e os ouvintes. Nesse sentido, a Libras pode agregar valores para essas relações ao estabelecer o diálogo e a interação 
transcultura ${ }^{5}$ sob a perspectiva da diversidade. Nessa perspectiva, Almeida (2013) argumenta que a Libras é um instrumento importante que possibilita a evolução das relações entre os Surdos e os ouvintes.

\section{Cultura Surda}

O povo Surdo brasileiro legou muitas tradições e histórias por meio de organizações, como, por exemplo, as associações, as federações e as igrejas. Essas organizações surgiram diante da necessidade dos Surdos terem um espaço para se reunirem e aprenderem a lidar contra as práticas ouvintistas que não respeitam a sua cultura (STROBEL, 2009).

Desse modo, a "cultura surda exprime valores e crenças que, muitas vezes, se originaram e foram transmitidas pelos sujeitos surdos de geração passada ou de líderes surdos bem-sucedidos, através das associações de surdos" (STROBEL, 2009, p. 29). Contudo, o termo cultura, na área da surdez, geralmente, está relacionado com a língua de sinais, com as estratégias sociais e com os mecanismos compensatórios que os Surdos desenvolvem e utilizam para agirem ativamente na sociedade.

Por exemplo, para Strobel (2008), existem oito artefatos culturais que ilustram a Cultura Surda, pois estão relacionados com os comportamentos e as atitudes de ser Surdo, de ver, de perceber e de modificar o mundo. Contudo, "o conceito 'artefatos' não se refere apenas a materialismos culturais, mas àquilo que na cultura constitui produções do sujeito que tem seu próprio modo de ser, ver, entender e transformar o mundo" (STROBEL, 2008, p. 39).

Esses artefatos culturais estão relacionados com: a) a experiência visual, que significa a utilização da visão, em substituição total à audição, como um meio de comunicação, b) os aspectos linguísticos da Libras, c) o aspecto familiar, que

${ }^{5} \mathrm{Na}$ interação transcultural, a comunicação efetiva ocorre quando o resultado do processo satisfaz às necessidades das partes envolvidas no diálogo. A interação transcultural que ocorre por meio da comunicação está sujeita a uma série de distorções que podem ser causadas pela semântica das palavras ou por outros fatores, como, por exemplo, o tipo de comunicação interpessoal que varia em diferentes estilos, como, por exemplo, do passivo para o assertivo (LIMONGI-FRANÇA, 2007). 
são os comportamentos próprios das famílias que possuem pessoas Surdas, d) a literatura Surda, através da memória das vivências surdas de várias gerações que se traduz em diversos gêneros, e) a vida social e esportiva, que são os relacionamentos socioculturais, f) as artes visuais, como as criações artísticas visuais, g) a política, que consiste em inúmeros movimentos e lutas do povo Surdo pelos seus direitos e h) os materiais, que são instrumentos utilizados para auxiliar na acessibilidade da vida cotidiana das pessoas Surdas (STROBEL, 2008).

Esses artefatos mostram as principais características da Cultura Surda, que estão relacionadas com os jargões, o conhecimento matemático e científico, as ideias, as crenças, a língua, os costumes e os hábitos próprios dessas comunidades. Para D'Ambrosio (1993), esse contexto se refere ao conjunto de ideias matemáticas utilizadas pelos membros de grupos culturais distintos, como, por exemplo, os trabalhadores urbanos e rurais, as classes profissionais e as sociedades indígenas, bem como de outros grupos específicos como os Surdos, que se identificam por meio de tradições comuns aos seus membros.

\section{O Programa Etnomatemática como uma ação pedagógica para a promoção da Educação Financeira}

O Programa Etnomatemática possui uma conceituação ampla e, por isso, é importante entender quais são os seus objetivos e como a sua ação pedagógica pode ser aplicada em sala de aula. Nesse contexto, um dos principais objetivos desse programa é analisar as práticas matemáticas realizadas pelos membros de um grupo cultural específico (D’AMBROSIO, 1990).

Então, Rosa (2010) argumenta que o Programa Etnomatemática possui diversas ações pedagógicas que valorizam os conhecimentos matemáticos dos membros de grupos culturais distintos que contribuem para a interação entre os alunos e os professores, tornando-os críticos para refletirem sobre os problemas enfrentados no cotidiano. 
Dessa maneira, o principal objetivo dessa abordagem é o desenvolvimento de um processo educacional que possibilite, para os alunos, a aquisição e a utilização dos instrumentos comunicativos, analíticos e materiais que são essenciais para o exercício de seus direitos e deveres intrínsecos à cidadania (D'AMBROSIO, 2009).

Nesse direcionamento, o Programa Etnomatemática se relaciona com a Cultura Surda por causa de suas questões sociais e práticas escolares, pois é no cotidiano que a sua ação pedagógica necessita se concretizar nos espaços escolares (ROSA, 2010). Assim, a Etnomatemática "restabelece a matemática como uma prática natural e espontânea" (D'AMBROSIO, 1993, p. 31) que é utilizada pelos membros de grupos culturais distintos.

Por conseguinte, esse programa também possibilita o processo de socialização dos membros pertencentes aos grupos minoritários, como, por exemplo, os Surdos, pois a matemática pode funcionar como um instrumento de empoderamento que contribui para melhorar a qualidade de vida e a dignidade nas relações humanas (ROSA; OREY, 2006).

Por exemplo, na perspectiva Etnomatemática, existe a necessidade de valorizar as experiências socioculturais dos alunos Surdos para que possam vincular os próprios conhecimentos matemáticos àqueles apresentados pelas instituições de ensino. Dessa maneira, o:

(...) ensino da matemática nesta concepção permitirá ao aluno vincular os conceitos trabalhando em classe a sua experiência cotidiana, de acordo com o seu ambiente natural, social e cultural. Não se trata de rejeitar a matemática acadêmica, mas sim incorporar a ela valores que são vivenciados nas experiências em grupo, considerando os vínculos histórico-culturais (CARNEIRO, 2012, p. 3).

De acordo com essa asserção, existe a necessidade de mergulharmos na dinâmica cultural existente em sala de aula para que possamos reconhecer no processo educativo o valor da Cultura Surda, bem como as suas influências para o processo de ensino e aprendizagem em matemática. 


\section{Relevância do Produto Educacional}

Os alunos Surdos chegam às escolas com ferramentas diferenciadas para classificar, medir, ordenar, quantificar, inferir e modelar, pois atuam de acordo com os recursos e restrições de seu meio. Dessa maneira, para que os estudantes Surdos possam exercer a cidadania, existe a necessidade da viabilização de um ambiente escolar que possibilite a sistematização dos saberes e fazeres adquiridos no ambiente sociocultural no qual estão inseridos.

Nesse contexto, as atividades desenvolvidas em sala de aula, que originaram esse produto educacional, tinham como objetivo propor uma maneira diferenciada de colocar a Matemática a serviço da Educação, direcionando os alunos Surdos para o desenvolvimento de sua autonomia e cidadania.

Um aspecto relevante desse produto educacional foi a inclusão da perspectiva da Etnomatemática na elaboração das atividades propostas com os conteúdos da Educação Financeira, possibilitando que o processo de ensino e aprendizagem em matemática fosse inserido no contexto sócio-histórico-cultural dos alunos Surdos.

Além disso, a fundamentação teórica apresentada na parte inicial desse produto possibilita o conhecimento e a reflexão sobre o contexto histórico, linguístico e cultural dos alunos Surdos para que, posteriormente, os educadores possam melhor planejar as estratégias educacionais que culminem com a inclusão e o desenvolvimento acadêmico dessa população escolar.

Por conseguinte, uma contribuição importante desse produto para a Educação Matemática é propiciar a ampliação do debate sobre as maneiras pelas quais a Etnomatemática pode contribuir para o desenvolvimento da ação pedagógica no contexto escolar ao trazer propostas educacionais mais próximas à realidade dos alunos Surdos.

Nesse sentido, o objetivo dessa abordagem é auxiliar os professores na promoção de uma educação que valorize a diversidade cultural, mas que também possibilite que esses alunos também tenham acesso ao conhecimento acadêmico. 
Dessa maneira, as atividades matemáticas, que foram elaboradas na perspectiva da Etnomatemática, para esse produto educacional, servem como um ponto de partida para aproximar os alunos dos conceitos relacionados com a Educação Financeira na prática cotidiana, revelando-se uma ferramenta importante para a compreensão de situações-problema vivenciadas diariamente.

Por exemplo, um dos aspectos relevantes do produto educacional está relacionado com a utilização do Programa Etnomatemática para o desenvolvimento da Educação Financeira dos alunos por meio da identificação da relação entre o conhecimento aprendido na escola e o conhecimento utilizado para resolver os problemas relacionados com atividades comerciais e financeiras praticadas diariamente. Nessa perspectiva, a utilização de informações provenientes do cotidiano dos alunos subsidiou a aquisição de conhecimentos da Educação Financeira por meio de uma ação pedagógica composta por atividades matemáticas contextualizadas e condizentes com a realidade dos Surdos.

O trabalho com os conteúdos da Educação Financeira, na perspectiva da Etnomatemática, utilizado nesse produto, possibilitou a (re)conciliação entre a escola e o cotidiano dos alunos Surdos por meio do estreitamento e do aprimoramento dessa relação. Essa estratégia possibilitou o desenvolvimento de competências e habilidades matemáticas necessárias para que esses alunos pudessem compreender as práticas comerciais e financeiras em seu cotidiano.

Dessa maneira, a contextualização da matemática, de acordo com a realidade sociocultural dos alunos Surdos, se evidenciou positivamente nas atividades propostas nesse produto, pois promoveu uma interação dinâmica entre esses alunos e o professor. Além disso, as trocas de ideias e experiências entre alunos Surdos e o professor possibilitaram que o conhecimento matemático fosse desenvolvido de maneira democrática em sala de aula.

Nesse sentido, Rosa (2015) argumenta que existe a necessidade que os professores reflitam sobre a maneira como as propostas pedagógica e metodológica são utilizadas em sala de aula, para que possam, a partir delas ou 
apesar delas, garantirem a construção de ambientes de aprendizagem mais democráticos para os alunos Surdos.

\section{Potencialidades de Utilização do Produto Educacional}

A pesquisa de mestrado da qual se originou esse produto educacional aponta alguns caminhos relevantes para o desenvolvimento da Educação Financeira de alunos Surdos, em uma perspectiva da Etnomatemática, por meio da elaboração de três blocos de atividades matemáticas denominado de: Sistema Monetário, Porcentagem, Lucro e Desconto.

Assim, as atividades propostas nesse produto educacional mostram que 0 primeiro passo para que os professores obtenham êxito no desenvolvimento da cidadania dos estudantes Surdos é a aquisição de conhecimentos sobre a Cultura Surda. O segundo passo é conhecer a língua desses alunos, que nesse caso é a Língua Brasileira de Sinais (Libras). O terceiro e último passo é a elaboração de atividades matemáticas que valorizem a Cultura Surda e que respeitem as potencialidades e limitações desses estudantes.

Desse modo, as atividades matemáticas propostas nesse produto, mostram que o conhecimento matemático está interligado às questões como, por exemplo, de economia, de sustentabilidade, de vida profissional, de vida financeira pessoal e familiar pode contribuir para o crescimento individual dos alunos Surdos e a sua inserção na sociedade. Nesse direcionamento, o produto educacional foi composto por três blocos de atividades:

O primeiro bloco, denominado História da Moeda e do Sistema Monetário Brasileiro, foi elaborado com atividades que buscaram valorizar os aspectos peculiares da Cultura Surda. Então, na elaboração dessas atividades foram utilizados materiais concretos manipuláveis e um projetor multimídia, bem como imagens, que tinha como objetivo o favorecimento das habilidades visuais dos alunos Surdos. O segundo bloco continha uma atividade sobre o tema 
Porcentagem, que foi trabalhada em Libras com os alunos Surdos por meio da realização de uma atividade lúdica denominada Adedanha ${ }^{6}$.

O terceiro bloco continha atividades sobre o conteúdo Lucro e Desconto, que foram ministradas em Libras. Essas atividades escritas foram elaboradas com enunciados curtos e com gravuras para auxiliar o desenvolvimento das habilidades visuais dos alunos Surdos. Esse bloco também continha uma dinâmica em grupo sobre o conteúdo de Lucro e Desconto. O quadro 01 mostra como esses três blocos de atividades foram distribuídos no produto educacional.

\begin{tabular}{|l|l|}
\hline \multicolumn{1}{|c|}{ Atividades } & \multicolumn{1}{c|}{ Objetivos } \\
\hline \multicolumn{2}{|c|}{ Bloco de Atividades 01: História da Moeda e do Sistema Monetário Brasileiro } \\
\hline $\begin{array}{l}\text { Atividade 01: } \\
\text { Palavras-cruzadas }\end{array}$ & $\begin{array}{l}\text { Reforçar as informações e os conceitos estudados sobre o sistema } \\
\text { monetário e a história da moeda. Reconhecer e identificar o dinheiro } \\
\text { brasileiro (cédulas e moedas). }\end{array}$ \\
\hline $\begin{array}{l}\text { Atividade 02: } \\
\text { Trabalhando com } \\
\text { dinheiro }\end{array}$ & $\begin{array}{l}\text { Contribuir para a aprendizagem dos alunos em relação à manipulação } \\
\text { do dinheiro para resolver problemas que envolvam operações } \\
\text { matemáticas. }\end{array}$ \\
\hline $\begin{array}{l}\text { Atividade 03: } \\
\text { Compras e troco }\end{array}$ & $\begin{array}{l}\text { Desenvolver as competências e habilidades dos alunos para resolverem } \\
\text { situações-problema do cotidiano, que envolvam a manipulação do } \\
\text { dinheiro. Revisitar os conceitos de compra, de pagamentos e de dar } \\
\text { trocos para conferir se estão corretos. }\end{array}$ \\
\hline \multicolumn{1}{|c|}{ Bloco de Atividades 02: Porcentagem } \\
\hline $\begin{array}{l}\text { Atividade 04: } \\
\text { Jogo Adedanha }\end{array}$ & $\begin{array}{l}\text { Resolver porcentagens de maneira descontraída e lúdica visando o } \\
\text { desenvolvimento do trabalho com autonomia e concentração. }\end{array}$ \\
\hline \multicolumn{1}{|c|}{ Bloco de Atividades 03: Lucro e Desconto } \\
\hline $\begin{array}{l}\text { Atividade 05: } \\
\text { Calculando Lucro e } \\
\text { Desconto }\end{array}$ & $\begin{array}{l}\text { Resolver problemas de lucro e desconto por meio da elaboração de } \\
\text { situações-problema do cotidiano. Realizar compras, efetuar o } \\
\text { pagamento, dar troco e conferir se o troco está correto. Desenvolver a } \\
\text { habilidade de calcular o preço de produtos que podem ser comprados } \\
\text { com o dinheiro disponível. }\end{array}$ \\
\hline $\begin{array}{l}\text { Aprender a comprar e vender produtos. Reconhecer e identificar o } \\
\text { dinheiro brasileiro (cédulas e moedas). Fazer compras, pagamentos, dar } \\
\text { troco e conferir se o troco está correto. Aprender a calcular o preço de } \\
\text { produtos que podem ser comprados com o dinheiro disponível. Discutir } \\
\text { sobre como economizar nas compras. }\end{array}$ \\
\hline Quadro 01: Bloco de Atividades Matemáticas \\
\hline $\begin{array}{l}\text { Finimercado } \\
\text { Fonte: Elaborado pelos autores }\end{array}$ \\
\hline
\end{tabular}

${ }^{6}$ Stop!, uestópe, istópi, adedanha ou adedonha é um jogo comum entre as crianças e adultos. Inicialmente, nesse jogo, desenha-se uma tabela em um papel para a utilização de cada um dos jogadores. Nesse desenho, cada coluna recebe o nome de uma categoria de palavras, como, por exemplo, animais, automóveis, nomes pessoais e cores enquanto cada linha representa uma rodada do jogo (PIROZZI, 2012). 
É importante ressaltar que todas as atividades descritas no quadro 01 foram originadas da dissertação de mestrado conduzida pelo primeiro autor e orientada pelo segundo. Contudo, as seis atividades relatadas no produto educacional foram aperfeiçoadas e acompanhadas por caixas de diálogos, denominadas dicas, sugestões e lembretes.

Essas caixas descrevem orientações, dicas e sugestões importantes para a condução dessas atividades. Além disso, apontam estratégias para auxiliar os professores e/ou intérpretes de Libras no desenvolvimento dessas atividades. $O$ quadro 02 mostra alguns exemplos de dicas que estão expressas no produto educacional.

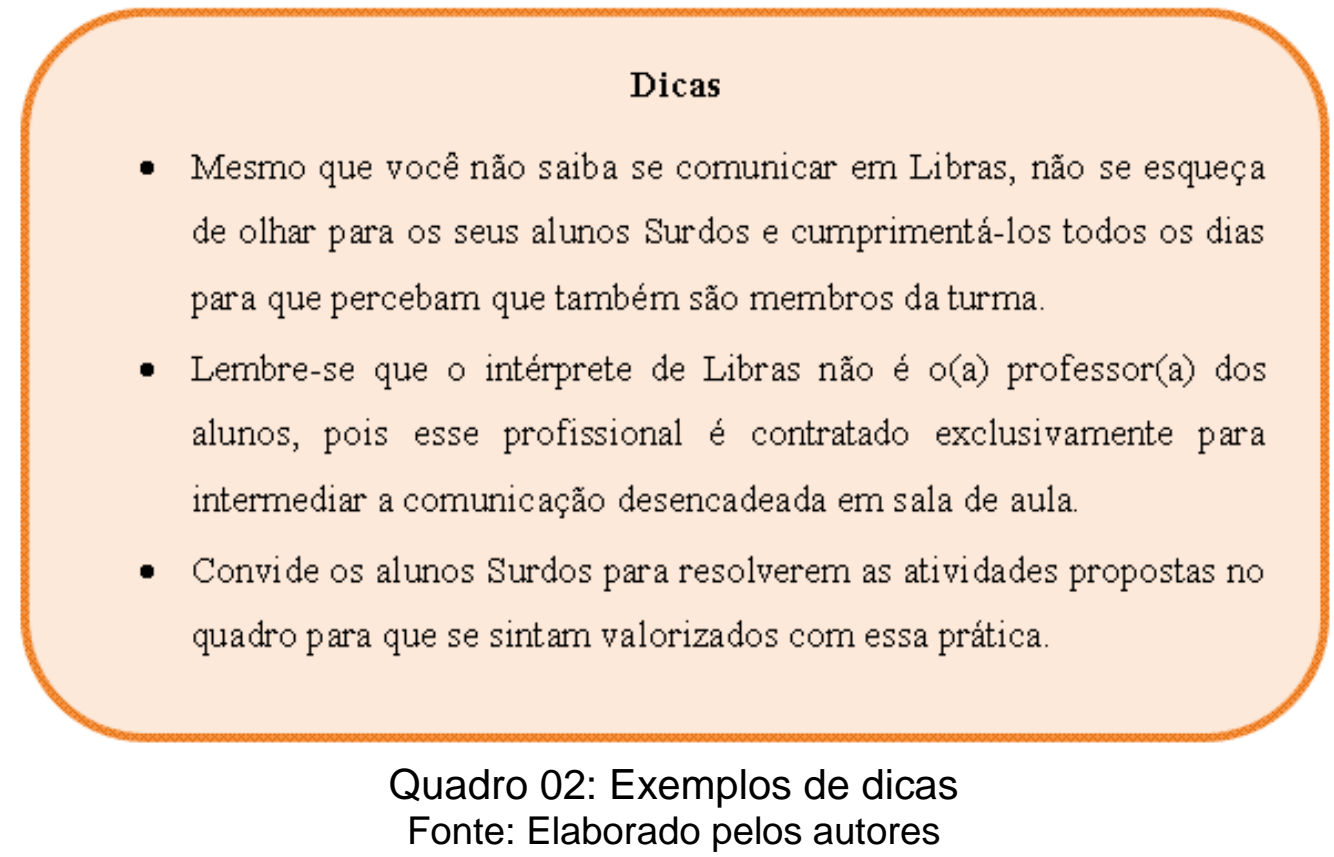

É importante enfatizar que as caixas de diálogos são fundamentais para estreitar a relação entre a pesquisa acadêmica e a prática pedagógica. Ressaltamos, também, que essas atividades foram elaboradas sob uma perspectiva Etnomatemática, pois tinha como objetivo propiciar a interação e a socialização entre os alunos Surdos, possibilitando que esses alunos construam as suas próprias estratégias para realizar os cálculos matemáticos, contribuindo, assim, para o desenvolvimento do conhecimento matemático e da Educação Financeira desses alunos de maneira dinâmica. 


\section{Considerações Finais}

De acordo com a perspectiva Etnomatemática, os alunos Surdos e ouvintes precisam adquirir os conhecimentos qualitativo e quantitativo para que possam perceber e reformular as relações matemáticas e o papel dessa área de estudo na sociedade para identificar e reconhecer os problemas que enfrentam no cotidiano. Nesse contexto, é importante que esses alunos processem as competências e habilidades necessárias para que possam entender, interpretar e refletir criticamente sobre os dados numéricos presentes nas atividades do cotidiano (MALLOY, 2002).

Nesse sentido, a perspectiva Etnomatemática, com relação ao estudo de conteúdos financeiros, representa um componente essencial para a interpretação de princípios de racionalidade econômica que orientam as argumentações que justificam as estruturas sociais existentes. No entanto, um dos maiores desafios dessa perspectiva está relacionado com o seu aspecto conceitual na Educação Matemática, pois é importante que os alunos consigam transitar do linear para o complexo, do quantitativo para o qualitativo e vice-versa (D'AMBROSIO, 2003), durante a resolução das atividades matemáticas curriculares propostas em sala de aula.

Assim, esse produto educacional mostra que esse processo deve incorporar os aspectos culturais do conhecimento matemático nas atividades curriculares propostas em sala de aula, pois tem como objetivo possibilitar a compreensão do caráter qualitativo dos conteúdos matemáticos quantitativos. Nesse sentido, ressaltamos que, de acordo com a perspectiva etnomatemática desse produto, existe a necessidade de que os professores valorizem as experiências socioculturais dos alunos Surdos para que possam vincular os próprios conhecimentos matemáticos àqueles apresentados pelas instituições de ensino. Dessa maneira, é importante ressaltar que o:

(...) ensino da matemática nesta concepção permitirá ao aluno vincular os conceitos trabalhando em classe a sua experiência cotidiana, de acordo com o seu ambiente natural, social e cultural. Não se trata de rejeitar a matemática acadêmica, mas sim incorporar a ela valores que são vivenciados nas 
experiências em grupo, considerando os vínculos histórico-culturais (CARNEIRO, 2012, p. 3).

Desse modo, todas as atividades curriculares apresentadas nesse produto educacional foram elaboradas sob a perspectiva da Etnomatemática, pois foram utilizadas questões contextualizadas e condizentes com o ambiente sociocultural no qual os alunos Surdos estão inseridos. Optamos também pela utilização de enunciados curtos na elaboração das situações-problema propostas devido à dificuldade que muitos desses alunos apresentaram em relação ao português escrito. Procuramos também valorizar as habilidades visuais desses alunos com a utilização de diversas imagens por meio da adaptação de dinâmicas metodológicas que pudessem contribuir para o desenvolvimento do conhecimento matemático e, consequentemente, da educação financeira dessa população escolar.

Então, consideramos que, nesse produto educacional, as atividades elaboradas sob a perspectiva Etnomatemática propiciaram um ambiente educacional que favoreceu o desenvolvimento da Educação Financeira dos alunos Surdos que se comunicam em Libras, pois por meio da contextualização foi possível compreender as soluções para as situações-problema retiradas do cotidiano. Dessa maneira, é importante que a prática pedagógica em sala de aula seja reorientada para o desenvolvimento da cidadania dos alunos Surdos. Nesse contexto, Pinheiro e Rosa (2016) argumentam que:

(...) é mister que os professores de matemática mergulhem na dinâmica cultural dos alunos e utilizem estratégias de ensino e aprendizagem que valorizem a dimensão cultural existente na sala de aula, para que se desenvolva uma educação matemática inclusiva que possa efetivamente contribuir para a transformação social (p. 79).

Em concordância com essa asserção, nesse produto educacional, o contexto cultural refere-se à cultura Surda dos membros desse grupo cultural específico de alunos. Por conseguinte, as atividades propostas buscaram a valorização da língua e da cultura desses alunos. Finalizando, essas atividades estavam relacionadas com a ação pedagógica do Programa Etnomatemática, pois 
a sua elaboração foi fundamentada nos pressupostos do Programa Etnomatemática, como, por exemplo, a promoção da socialização entre os alunos Surdos e ouvintes, a valorização de suas culturas e a minimização dos preconceitos.

\section{Referências}

ALMEIDA, W. G. Introdução à língua brasileira de sinais. Ilhéus, BA: UAB/UESC, 2013.

BISOL, C. A.; VALENTINI, C. B. Surdez e deficiência auditiva - qual a diferença? Objeto de Aprendizagem Incluir. UCS/FAPERGS, 2011a. Disponível em <<http://www.grupoelri.com.br/Incluir/downloads/OA_SURDEZ_Surdez_X_Def_Audit_Tex to.pdf $>>$. Acesso em 20 de Janeiro de 2018.

BISOL, C. A.; VALENTINI, C. B. O Alfabeto manual. Objeto de Aprendizagem Incluir UCS/FAPERGS, 2011b. Disponível em:

<http://www.grupoelri.com.br/Incluir/downloads/OA_SURDEZ_Alfabeto_Manual_Texto.pdf .> Acesso em 07 de Janeiro de 2018.

BORDINHON, T. Filosofias educacionais para Surdos. Trabalho apresentado no $\mathrm{X}$ Congresso de Educação do Norte Pioneiro. Jacarezinho, PA: UENP, 2010. Disponível em <<http://www.uenp.edu.br/trabalhos/cj/anais/congressoEducacao2010/Thiago\%20Bordinh on\%20(2).pdf>> Acesso em 12 de Janeiro de 2018.

BRASIL. Lei no 10.436, de 24 de abril de 2002. Dispõe sobre a Língua Brasileira de Sinais: Libras. Disponível em $<<$ http://www.planalto.gov.br/ccivil_03/LEIS/2002/L10436.htm>> Acesso em 12 de Janeiro de 2018.

BRASIL. Decreto $n^{\circ} 5.626$, de 22 de dezembro de 2005. Dispõe sobre a Língua Brasileira de Sinais: Libras Disponível em <<http://www.planalto.gov.br/ccivil_03/_ato2004-

2006/2005/decreto/d5626.htm>>. Acesso em 12 de Janeiro de 2018.

BRITO, L. F. Integração social e educação de surdos. Rio de Janeiro, RJ: BABEL Editora, 1993.

CAPOVILLA, F. C. Filosofias educacionais em relação ao Surdo: do oralismo à comunicação total ao bilinguismo. Revista Brasileira de Educação Especial, v. 6, n. 1, p. 99-116, 2000.

CARNEIRO, K. T. A. Cultura Surda na aprendizagem matemática da sala de recurso do Instituto Felipe Smaldone: uma abordagem etnomatemática. Anais do 4º Congresso Brasileiro de Etnomatemática. Belém, PA: ICEm4, 2012.

D’AMBROSIO, U. Etnomatemática. São Paulo, SP: Editora Ática, 1990. 
D'AMBROSIO, U. Etnomatemática: um programa. Educação Matemática em Revista, v. 1, n. 1, p. 5-11, 1993.

D'AMBROSIO, U. Educação matemática: da teoria à prática. São Paulo, SP: Editora Papirus, 1996.

D’AMBROSIO, U. História, etnomatemática, educação e modelagem. XI CIAEM Blumenau, SC: FURB, 2003.

D’AMBROSIO, U. O programa etnomatemática: uma síntese. Acta Scientiae, v. 10, n. 1, p. 7-16, 2008.

D'AMBROSIO, U. Etnomatemática - elo entre as tradições e a modernidade. Belo Horizonte, MG: Autêntica, 2009.

DINIZ, H. G. A história da Língua de Sinais Brasileira (Libras): um estudo descritivo de mudanças fonológicas e lexicais. 2010. Dissertação (mestrado). Florianópolis, SC: UFSC 2010.

FERREIRA, A. B. H. Miniaurélio Século XXI Escolar: O minidicionário da língua portuguesa. Rio de Janeiro: Nova Fronteira, 2000.

FERREIRA BRITO, L. Integração social \& educação de Surdos. Rio de Janeiro, RJ: Batel, 1993.

HONORA, M.; FRIZANCO, M. L. E. Livro ilustrado de Língua Brasileira de Sinais: desvendando a comunicação usada pelas pessoas com surdez. II Título. São Paulo, SP: Ciranda Cultural, 2009.

KYLE, J. O ambiente bilíngue: alguns comentários sobre o desenvolvimento do bilinguismo para os surdos. In: SKLIAR, C. (Org.). Atualidade da educação bilíngue para surdos: processos e projetos pedagógicos. Porto Alegre, RS: Mediação, 1999. pp. 15-26.

LIMONGI-FRANÇA, A. C. Práticas de recursos humanos - PRH: conceitos, ferramentas e procedimentos. São Paulo, SP: Atlas, 2007.

MALLOY, C. E. (2002). Democratic access to mathematics through democratic education. An introduction. In L. D. ENGLISH (Ed.). Handbook of international research in mathematics education. Mahwah, NJ: Erlbaum, 2002. pp. 17-25.

MOURA, M. C. O surdo: caminhos para uma nova identidade. Rio de Janeiro, RJ: Revinter, 2000.

PERLIN, G. T. História dos Surdos. Florianópolis, SC: UDESC/CEAD, 2002.

PERLIN, G. T.; STROBEL, K. Teorias da educação e estudos surdos. Florianópolis, SC: CCE/UFSC, 2009. 
PINHEIRO, R. C.; ROSA, M. Uma perspectiva etnomatemática para o processo de ensino e aprendizagem de alunos Surdos. RPEM, v. 5, n. 9, p. 56-83, 2016.

PIROZZI, G. P. A importância do lúdico e da atividade recreativa na educação de crianças. Oficina: Brinquedos \& brincadeiras: unindo o passado ao presente. Anais do VIII Congresso de Educação de Salto: Educação Integral. Salto, SP: Secretaria da Educação - Prefeitura da Estância Turística de Salto. pp. 1-12

QUADROS, R. M.; KARNOPP, L. Língua de sinais brasileira: estudos linguísticos. Porto Alegre, RS: ArtMed, 2004.

REDONDO, M. C. F.; CARVALHO, J. M. Deficiência auditiva. Brasília, DF: MEC. Secretaria de Educação a Distância, 2000.

ROSA, M. A mixed-methods study to understand the perceptions of high school leaders about English Language Learners (ELL) students: the case of mathematics. Tese de Doutorado. College of Education. Sacramento, CA: California State University, Sacramento - CSUS, 2010.

ROSA, M. Etnomatemática e a formação de professores de matemática. Palestra proferida no 3록 SAMAT e 1ํEMASSP. Marabá, PA: FAMAT/UNIFESSPA, 2015.

ROSA, M.; OREY, D. C. Abordagens atuais do programa etnomatemática: delinenandose um caminho para a ação pedagógica. BOLEMA, v. 19, n. 26, p. 19-48, 2006.

STROBEL, K. As imagens do outro sobre a cultura surda. Florianópolis. Editora UFSC. 2008.

STROBEL, K. História da educação de Surdos. Florianópolis, SC: UFSC, 2009.

Disponível em:

<<http://www.libras.ufsc.br/colecaoLetrasLibras/eixoFormacaoEspecifica/historiaDaEduca caoDeSurdos/assets/258/TextoBase_HistoriaEducacaoSurdos.pdf $>>$. Acesso em 12 de Janeiro de 2018.

STROBEL, K. L.; FERNANDES, S. Aspectos linguísticos da LIBRAS. Curitiba, PR: SEED/SUED/DEE, 1998. 